Provided for non-commercial research and education use. Not for reproduction, distribution or commercial use.

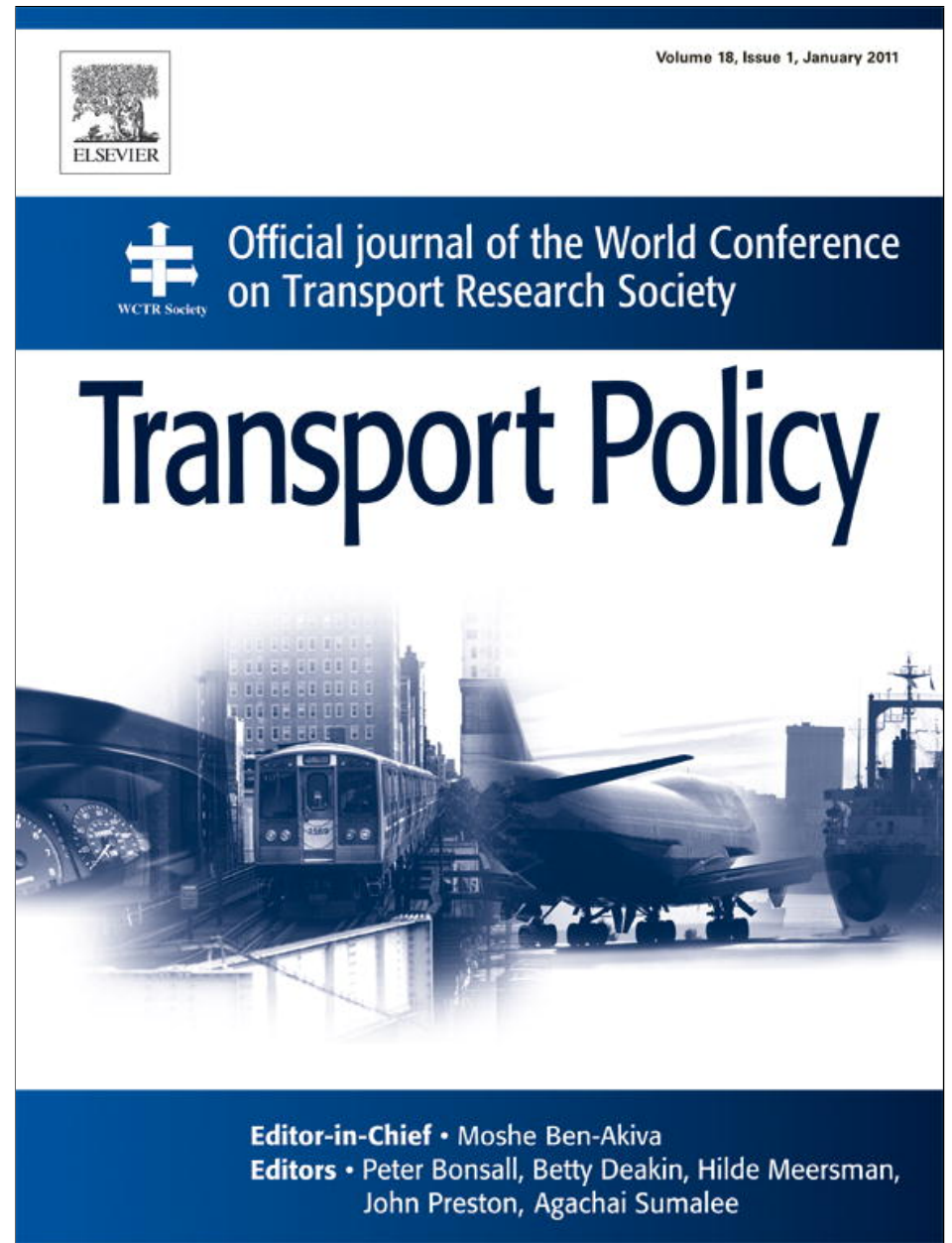

(This is a sample cover image for this issue. The actual cover is not yet available at this time.)

This article appeared in a journal published by Elsevier. The attached copy is furnished to the author for internal non-commercial research and education use, including for instruction at the authors institution and sharing with colleagues.

Other uses, including reproduction and distribution, or selling or licensing copies, or posting to personal, institutional or third party websites are prohibited.

In most cases authors are permitted to post their version of the article (e.g. in Word or Tex form) to their personal website or institutional repository. Authors requiring further information regarding Elsevier's archiving and manuscript policies are encouraged to visit:

http://www.elsevier.com/copyright 


\title{
The hierarchy of roads, the locality of traffic, and governance
}

\author{
David Levinson, Shanjiang Zhu* \\ University of Minnesota, Department of Civil Engineering, 500 Pillsbury Drive SE, Minneapolis, MN 55455, USA
}

\section{A R T I C L E I N F O}

Keywords:

Transportation financing

GPS

Road utilization

Hierarchy of roads

Transportation governance

\begin{abstract}
A B S T R A C T
This study investigates the use of road networks both within and outside of home jurisdictions (city (or town) and county of residence) by analyzing GPS data collected in the Minneapolis-Saint Paul metropolitan area. The study tracked volunteers' travel behavior to determine which roads (and thus which class of roads) users chose to accommodate their travel needs. More than half of the travel on county roads and city streets occur outside of one's home city, but most travel is within one's home county. The average share of travel distance in the home county is more than $70 \%$ for both county and city streets. The high share, which does not account for non-residents destined for the county to work or shop, e.g., implies that the free rider problem on city and county streets at the county level is minimal. Of particular concern is travel on city roads in cities other than one's own. To the extent that this is to go to a destination in that city, that travel is also local. However, because city and county roads are typically funded by those jurisdictions from land-based sources such as property taxes, through trips with neither end in the city through which they are traveling are in a very real sense "free riders", and pose a problem. With growing trip lengths and emerging economies of scale in road management, it may be appropriate to consider moving more roads from township, town, or city level to the county level of government.
\end{abstract}

(c) 2011 Elsevier Ltd. All rights reserved.

\section{Introduction}

Should the federal, state, or municipal government be accountable for financing, building, operating, or maintain a particular road? Both road networks and governments are typically hierarchically organized. However, the nature and degree of hierarchy varies. Governing a network link by a jurisdiction that is inappropriately small (or inappropriately large) adds costs avoidable by associating the infrastructure with the most appropriate layer of government.

Highways and streets serve two distinct functions: through movement and land access. The hierarchy of roads separates these functions to achieve several benefits (and incur several related costs):

- Aggregates traffic to achieve economies of scale in construction and operation, a particular advantage for expensive, limitedaccess facilities. Aggregation makes the construction of grade separations feasible, for instance.

- Reduces traffic conflicts by separating the access and movement function.

\footnotetext{
* Corresponding author. Tel.: +16125320987.

E-mail addresses: dlevinson@umn.edu (D. Levinson), zhuxx120@umn.edu (S. Zhu).

URL: http://nexus.umn.edu (D. Levinson).
}

- Maintains the desired quiet character of residential neighborhoods by keeping through traffic away from homes (but doing so increases travel distance).

- Contains less redundancy, and so may be less costly to build (but more vulnerable and less robust).

- Enables efficient network financing by establishing excludability associated with higher levels and the separability associated with each layer. In economic terms, the top level is potentially a competitive market good, while the bottom level is a public or club good.

In North America, the hierarchy of roads emerged early in the eighteenth century with the division of roads into Great (or Kings) Highways and Common Highways. Great Highways were under the authority of a colony's Governor and Council, while Common Highways were managed more locally by appointed commissioners or the county court upon presentment of a grand jury or petition (Durrenberger, 1931). Similarly today, roads serving longer-distance trips are generally controlled by a higher jurisdiction than those tending to serve shorter-distance traffic.

Political jurisdictions in the United States range from homeowner associations (which are not a true layer of government, but provide many what are traditionally considered local government services (McCabe and Tao, 2006)) at the lowest level, through townships, towns, or cities to counties, to states and then the federal government at the highest level. Different layers of government 
typically have different functions: A homeowners' association may manage common property and driveways; a township may provide township roads; a county provides medium sized roads; while the state retains large roads. The federal government shares revenue among states providing a large share of funding for major transportation projects (such as Interstate Highways).

Which level of government should manage or regulate which level of the network? Or, more precisely, where should the lines be drawn between roads managed by municipal, county, and state governments, respectively?

Surprisingly, there has been little attention paid to the question of correspondence between the locality of travel and road ownership. This may have been due partly to the absence of a perceived problem with existing structures of local road finance. Another reason why this question may not have been posed previously is the lack of adequate data. Until recently, travel behavior data sets have been predominantly trip-based and not sufficiently detailed to capture complex patterns of urban travel.

To bridge this gap, this study investigates the usage of road networks both within and outside of home jurisdictions (city (or town) and county of residence) by analyzing GPS data collected in the Minneapolis-Saint Paul metropolitan area, which tracked volunteers' travel behavior to determine which roads (and thus which class of roads) users chose to accommodate their travel needs. Specific attention is given to travel off of the principal arterial network.

This study complements previous work which aimed to establish the optimal mix between state and county funding based on minimizing economic costs (Levinson and Yerra, 2002). Instead of considering cost distribution, this study examines utilization.

The next section summarizes current funding arrangements. The underlying theory of correspondence between jurisdiction of residence and jurisdiction of provision is presented. Then the paper describes the study area and detail of the GPS data. The amount of travel occurring on different classes of roads managed by different jurisdictions is then analyzed. The paper concludes with a discussion of policy implications for transportation finance that can be derived from this study.

\section{Current funding arrangements}

The mixed experience of alternative funding mechanisms indicates that any revenue source trades off between administrative efficiency, equity, political acceptability, etc. There is no universal best mix of funds, it depends very much on the context of the specific place and time. Current transportation funding is a mix of federal, state, local sources, and a mix of user, non-user beneficiary, and general public revenue sources. Fig. 1 shows United States average and Minnesota transportation funding for state and local governments. As can be seen from the figures, while large parts come from user fees collected at the state level, local transportation funding largely depends on local general funds (which are often from property taxes) as well as specific dedications similar to property taxes. Each state differs in this allocation, but the general pattern remains that many funds, especially for local transportation, are funded based on property value rather than user fees. Nationally the ratio of state to local funding is about 2:1, while in Minnesota, the ratio is closer to $1: 1$.

Financing arrangements adopted by local jurisdictions in the United States (primarily cities, but also counties) that rely heavily on property taxes or other local, broad-based taxes implicitly assume that most travel on roads in these jurisdictions is local in nature. If this assumption holds, then most of the benefits from local roads accrue to local residents and it is reasonable to impose charges on these residents to finance the roads. The property tax is collected in any case, so using an existing revenue source is administratively efficient for local governments. If this assumption does not hold, there may be a substantial amount of free-riding by travelers on local networks outside their home jurisdiction.

\section{Service areas and the correspondence problem}

A service area is defined as the area from which all trips on a link either originate or for which they are destined, whichever trip end is closer (Levinson, 2002). The service area concept is illustrated Fig. 2, in which the city in the upper right hand corner is the service area for the city road it surrounds. The county is the service area for the larger county road it contains. This particular figure is idealized (though the use of circular roads and the absence of through streets). The real world is quite a bit messier.

While all traffic originating in or destined for its service area is by definition local, the term local is relative as that local area may be large for facilities at the top of the hierarchy, links that serve long-distance trips.

For any size jurisdiction, the share of local (own-jurisdiction originating or destined) traffic is highest on streets lower in the hierarchy. In the illustration, $100 \%$ of City Road traffic was local to the City, but only a fraction of County Road traffic was local to the city. That fraction depends on the amount of through traffic and within-city traffic using County Road. If there is no through traffic, all traffic on the County Road is local to the City.

The reason for defining a service area is to determine the appropriate geography for transportation management (and consequently financing) for a given facility. This is especially important when users cannot be charged directly. It seems clear that if there is a geography to which a link should be assigned, it should be based on the origin and destination of trips using that link. Further, it seems clear that a host pays rule, where the nearest trip-end plays host, is practical compared with its alternatives: guest pays or split the bill. Guest pays involve billing the individual (or, more specifically, the jurisdiction in which he lives) from the farther zone, which would mean collecting revenue and involving decision-makers from many zones rather than a few. This is traditionally used to pay for land-line telephone calls, where the caller pays. A split the bill rule involves more calculations still, as the management must be divided among all zones that use the link, regardless of how small. This is used in mobile-phone billing. While the nearest zone is spatially concentrated with many users, the farther zones each have only a few users, but there are many such zones. Because there is a general symmetry in trip-making (each trip has two ends, most trips are round trips), and both parties at a trip-end receive benefits (employer/employee, vendor/customer), adopting a host pays rules should work out to be approximately fair. One can imagine problems (unwanted traveling salesmen, for example), but this is seemingly a small issue (compared with, say, unwanted telemarketers).

One difficulty with host pays is the multiplicity of hosts. For a street, is the appropriate host the local neighborhood association, municipality, county, or state? Some share of traffic on the street is local to each of those jurisdictions.

Buchanan and Tullock (1962) provide an argument in favor of local and decentralized decision-making. They suggest that larger governments are more subject to logrolling (parliamentary votetrading). In logrolling, the traded votes are for projects of purely local interest, that is, 'pork barrel' projects. Overspending results from allowing these local projects to be funded more globally. The costs are diffuse over the entire population, while the benefits are concentrated. So the incentive for getting the larger community to pay for a local project is high, particularly so when other local areas are playing the same game.

Logrolling is common in democracies, and can be reduced by making government more local so that for instance, only the 

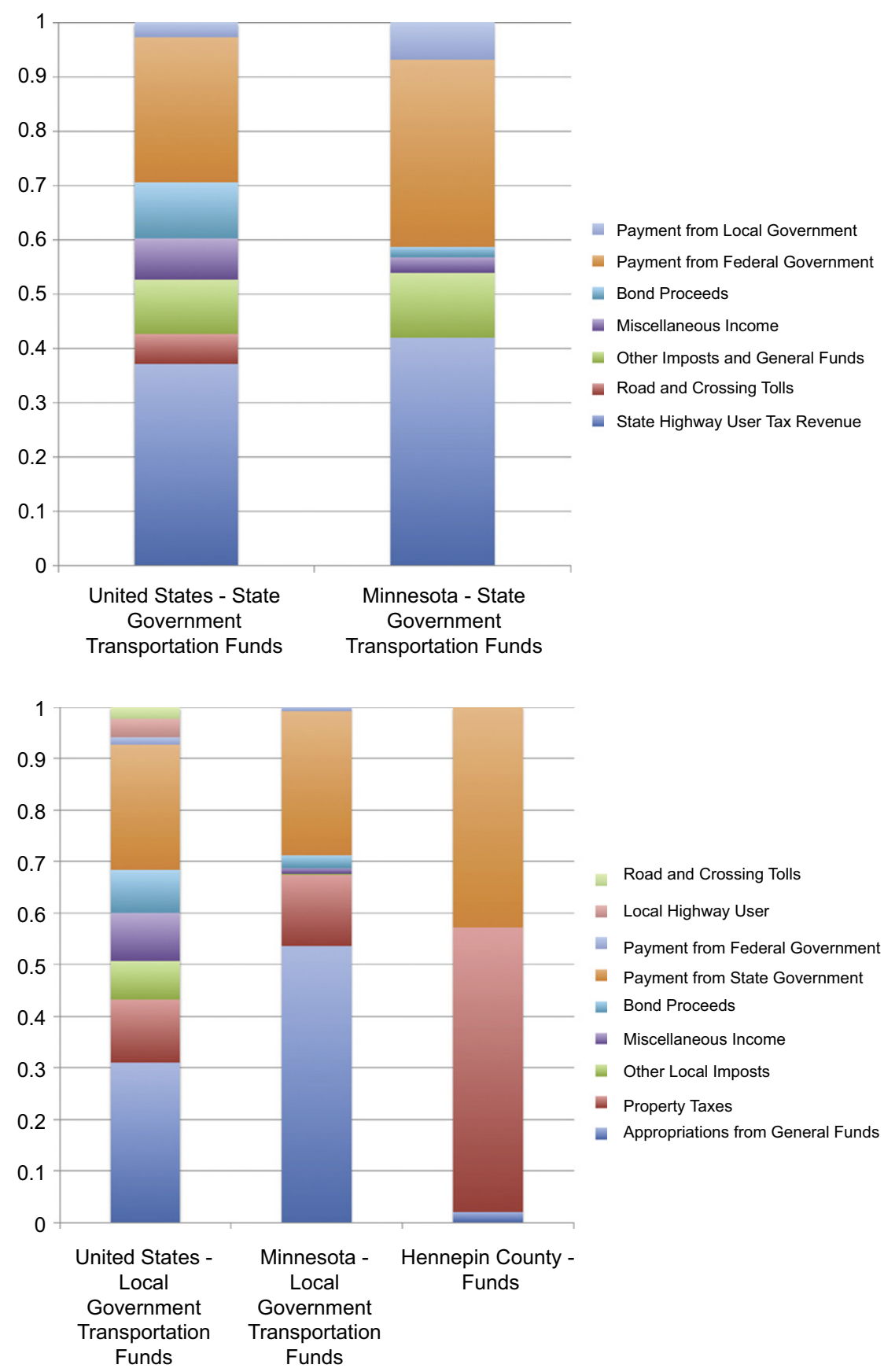

Fig. 1. Transportation funding in the United States and Minnesota. Source: US Federal Highway Administration (2009) Highway Statistics 2008 Tables LGF21 and SF21.

beneficiaries of a project pay for it. For example, a rule could be formulated that road segments are assigned to the smallest jurisdiction on which $50 \%$ of trips are locally originating or destined. The appropriate percentage could still be debated.

This paper examines the actual percentage of local traffic for jurisdictions in Minnesota beginning with the next section. Comparing the actual level with the most efficient level is important to know if and how public policy about which jurisdictions control which roads should change. This answer is not static, as transportation links increase in speed, we would expect they be upgraded in ownership as well (Xie and Levinson, 2009). The most efficient level is also an empirical question, trading off costs of higher levels of government such as logrolling against economies of scale.

Another alternative would be to establish new government or management organizations for roads to improve fit, but this runs the risk of increasing the oversight burden for those who now have to monitor multiple single-issue government agencies (which is common in some areas) rather than monitor fewer, multiple-issue agencies. Table 1 summarizes the basic hypotheses that are suggested when a lower or higher level of government manages roads that serve short- or long-distance trips. The mismatch of the jurisdiction with the appropriate public issue is often called the Correspondence Problem.

Advantages and disadvantages to managing roads under a higher jurisdiction are listed below, extending and summarizing (Levinson, 2002):

- Benefits

$\circ$ A larger jurisdiction is more able to achieve the various kinds of scale economies. 


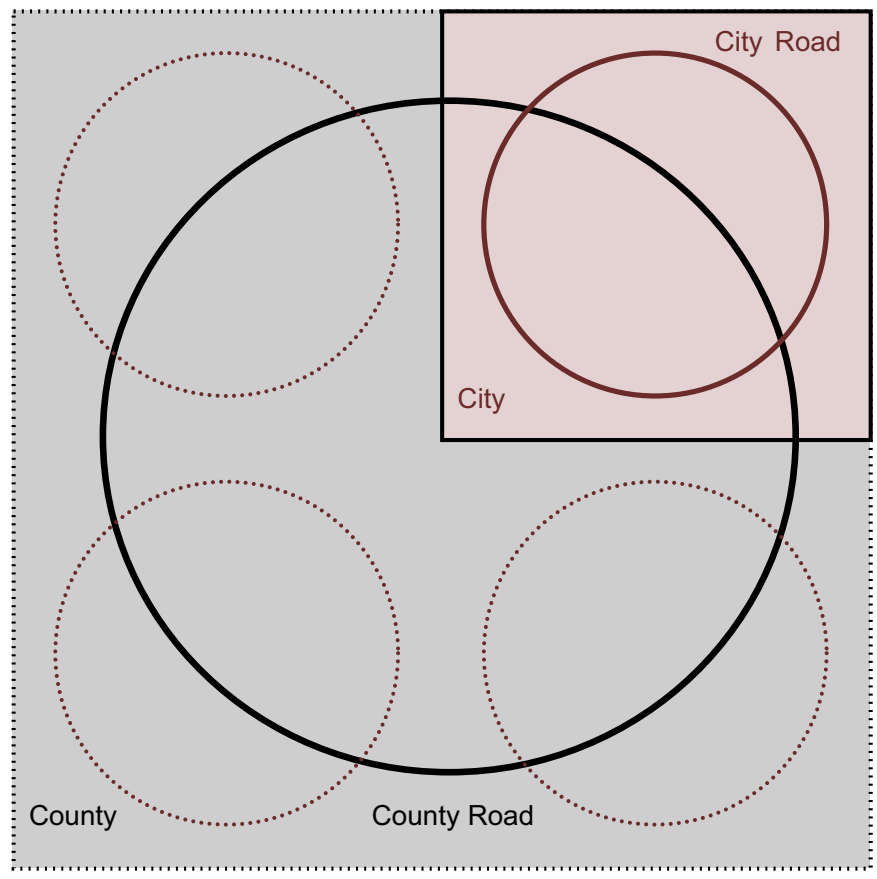

Fig. 2. Network service areas corresponding to jurisdictions Ideal Model of Hierarchy.

Table 1

Correspondence problem with logrolling.

\begin{tabular}{lll}
\hline & Short-distance road & Long-distance road \\
\hline $\begin{array}{l}\text { Municipal government } \\
\text { State government }\end{array}$ & $\begin{array}{l}\text { Fair and efficient } \\
\text { Overinvest or underprice }\end{array}$ & $\begin{array}{l}\text { Underinvest or overprice } \\
\text { Fair and efficient }\end{array}$ \\
\hline
\end{tabular}

The chain of governance is clearer the fewer governmental layers there are.

o Inter-jurisdictional welfare loss in decision-making, and gouging of neighbors with excessive tolls is eliminated (Levinson, 2002).

- Costs

- Larger jurisdictions have a larger span of control, which increases management costs and slows decision times.

$\circ$ Decisions are made remotely with less information about site-specific circumstances (Hayek, 2001), the principal agent problem is worsened in this circumstance as government is farther from the people

- Logrolling costs lead to overinvestment (or perhaps underpricing).

o Innovation loss, as fewer experiments can be run when there are fewer competing independent governments operating.

- Product differentiation is diminished (in the Tiebout Hypothesis sense, Tiebout, 1956), as there are fewer combinations of taxes and differentiated public services provided to allow taxpaying consumers to choose alternative jurisdictions.

o Higher jurisdictions are more likely to use tax financing rather than tolls, which makes congestion pricing more difficult to implement (Levinson, 2002).

\section{GPS data}

This study focuses on the Twin Cities Metropolitan Area (7 County) which contains 7 counties and 190 cities. Fig. 3 presents the jurisdiction boundaries and major roads in the region. We are interested in the question of how much travel takes place by jurisdiction and class of roads. To answer this question, this study employs GPS data collected during a travel behavior study after the I-35W Bridge collapse (Zhu et al., 2010). The objective of the GPS-based study is to capture commuters' travel behavior

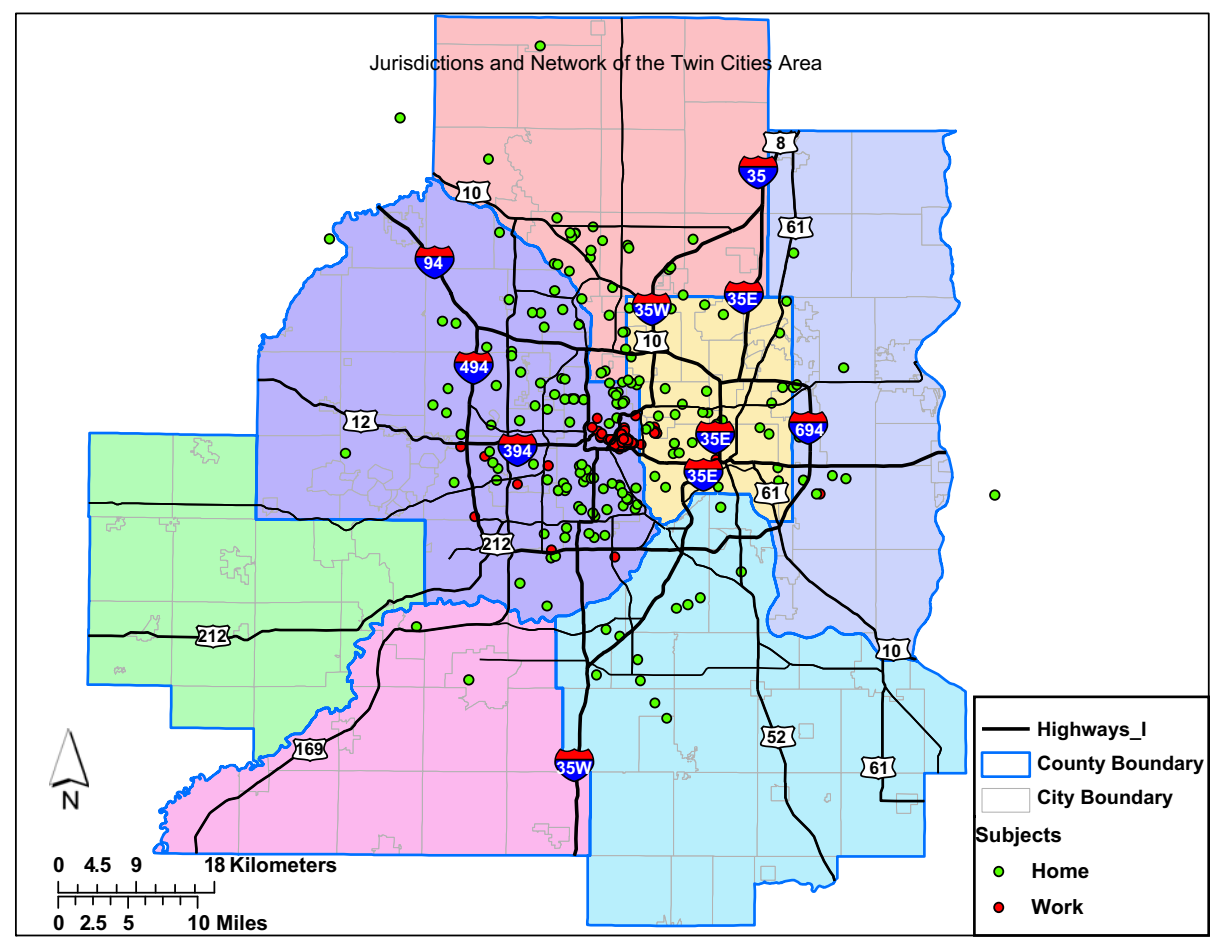

Fig. 3. The study area and the home and work locations of study subjects. 
through longitudinal observations of travel choices participants made during the opening the I-35W replacement bridge. Subjects were randomly selected among more than 1000 respondents to our recruiting announcements posted through different media, including Craigslist and City Pages, flyers at grocery stores, flyers at city libraries, postcards handed out in downtown parking ramps, and emails to more than 7000 University of Minnesota staff (students and faculty were excluded).

The home and work locations of all subjects are also indicated in Fig. 3. The subjects' home locations spread widely across the region, though their work locations concentrate in the downtown Minneapolis and the University of Minnesota campus. Since this study focuses on the association between the locality of travel and home jurisdiction, we believe the bias in our sample is limited.

GPS devices were installed in the vehicles of subjects and monitored their trajectories during a study period lasting from 8 to 13 weeks. All trips made, including both work and non-work, were recorded and analyzed on $24 / 7$ basis.

Excluding cases affected by device failure or early exit from the study, data from 140 subjects were collected. Two different technologies were used. Vehicles of 97 subjects were equipped with logging Global Positioning System (GPS) devices (QSTARZ BT-Q1000p GPS Travel Recorder powered by DC output from invehicle cigarette lighter), which recorded locations along the vehicle trajectory every $25 \mathrm{~m}$. A more reliable (and pricier) GPS data collection system developed by Professor Randall Guensler of the Georgia Institute of Technology and the subcontractor Vehicle Monitoring Technologies (VMTINC) was adopted for 43 subjects, which transmitted a second by second position log to the Atlanta-based server in real time through wireless communication systems.

Algorithms are developed to convert position log data from both sources into trip information under ArcGIS. Details of this process is described by Zhu et al. (2010). The link sequence of a trip is built to finding the nearest link of a trajectory point that:

- is consistent with travel direction of previous and subsequent points,

- generates reasonable travel speed, and

- connects logically with upstream and downstream links.

Since we focused on the 7 county Twin Cities area (Anoka, Dakota, Hennepin, Ramsey, Scott, Washington, and Carver Counties), potential subjects who live outside of the study area (e.g., in the 13 "collar county" area, including parts of Wisconsin) were excluded. Long-distance travel that leaves the study area is also excluded.

Home addresses were provided by study participants. They are digitized in ArcGIS and verified visually by comparing with GPS data. The home county and home city of each subject is identified by overlaying their home locations and the digital map of political boundaries (thereby determining their township, town, or city (or if they live in an unincorporated area) as well as their county and state, Minnesota).

\section{Network}

A detailed network conflated to the real road geometry (The TLG network ${ }^{1}$ ) is used in this study. It covers the 7-county Twin Cities Metropolitan Area and is the most accurate GIS network map to date. The original TLG network contains both

${ }^{1}$ The TLG network is generated and maintained by the Metropolitan Council and The Lawrence Group (Craig, 2005). two-directional and one-directional links. In order to be consistent with geo-coding conventions of planning network, all twodirectional links are converted into two links (one in each direction). The modified TLG network contains 290,231 links, providing an accurate description of the entire Twin Cities network to the street level.

The functional class of road feature separates the TLG road files. The functional classes consist of A10 Interstate Freeways, A15 Interstate HOV lanes (I-394 HOV), A20 US Highways, A25 State Highways, A30 County Road, A40 City Street, A63 Ramps and Loops, and A64 Service Drives. Ramps and loops are not treated independently and instead are regrouped to the corresponding road classes in this study.

There are 190 cities within the 7-county metropolitan area. Jurisdictional fragmentation has lead to numerous agencies building, operating, and maintaining different functional classes of roads. Classes A30 (County Road) and A40 (City Street), are specifically examined for the purpose of this study. The objective is to evaluate the extent to which travel on low level roads is local in nature.

\section{Locality of travel}

By skimming the network according to the link sequences previously derived and comparing the satellite time recorded in GPS data, we evaluate the total travel that take places on different road functional classes by both time and distance. Fig. 4 summarizes the share of vehicle distance and hours on different roads for weekdays and weekends. For weekday commuters in our study, $38 \%$ of all travel distance is on the Interstate. Other state highways represent only $22 \%$ of travel distance. The share of travel distance is greater on fast roads, while the share of travel time is unsurprisingly greater on slow roads. Weekends show similar patterns, with about $4 \%$ less Interstate Highway travel. The share of Interstate Highway VKT from this study is higher than the 23.9\% cited by Wachs (2003) from Federal Highway Administration's Highway Statistics. Since subjects in our study live mostly in suburban areas, and all were commuters, it is not surprising to see a somewhat heavier use of Interstates.

Fig. 5 summarizes the average percentage of travel distance that takes place in one's home county and city among all subjects. Considering the relatively large size of counties in Minnesota, it is not surprising to find that most people make the majority of travel in their home county (local in nature), regardless of road class. The average share of VKT in the home county is more than $70 \%$ for both county and city streets. The high share, which does not even account for non-residents destined for the county to work or shop, e.g., implies that the free rider problem on city and county streets at the county level is minimal.

On average, only about $42 \%$ of VKT on county roads takes places in one's home city. Only half of the travel on city streets is in one's own city. The average percentage of travel in the home city is much lower for Interstate highways (23\%), US highways (9\%), and State highways (21\%). Fig. 6 shows the distribution of travel on county and city roads, there is a wide variance, both because of very different travel behaviors across individuals and differences in the nature of city and county road networks.

Not all non-local travel is detrimental to system efficiency with land-based financing because there is a general symmetry in tripmaking (each trip has two ends, most trips are round trips), and both parties at a trip-end receive benefits (employer/employee, vendor/customer), adopting a host pays rules should work out to be approximately fair. Of particular concern is through traffic with neither end in the city or county through which they are traveling. These travelers are in a very real sense "free riders" since 


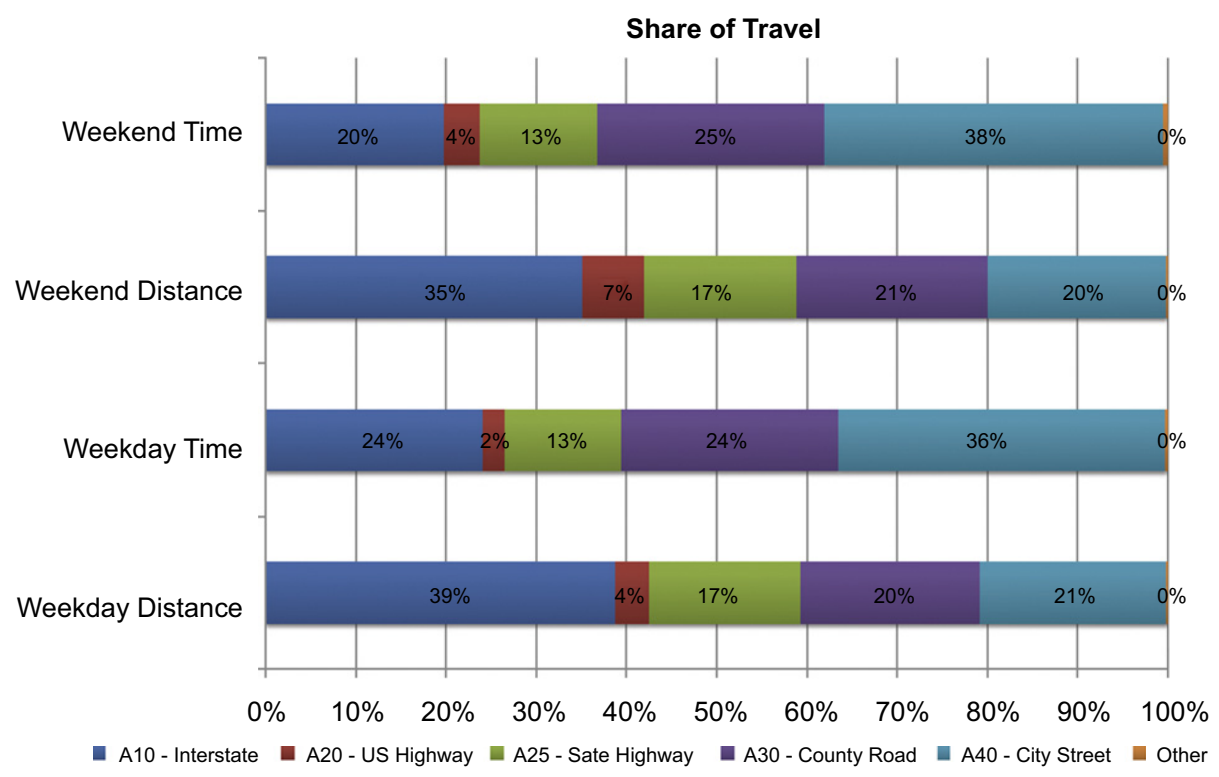

Fig. 4. Vehicle travel on different roads during weekday and weekend.

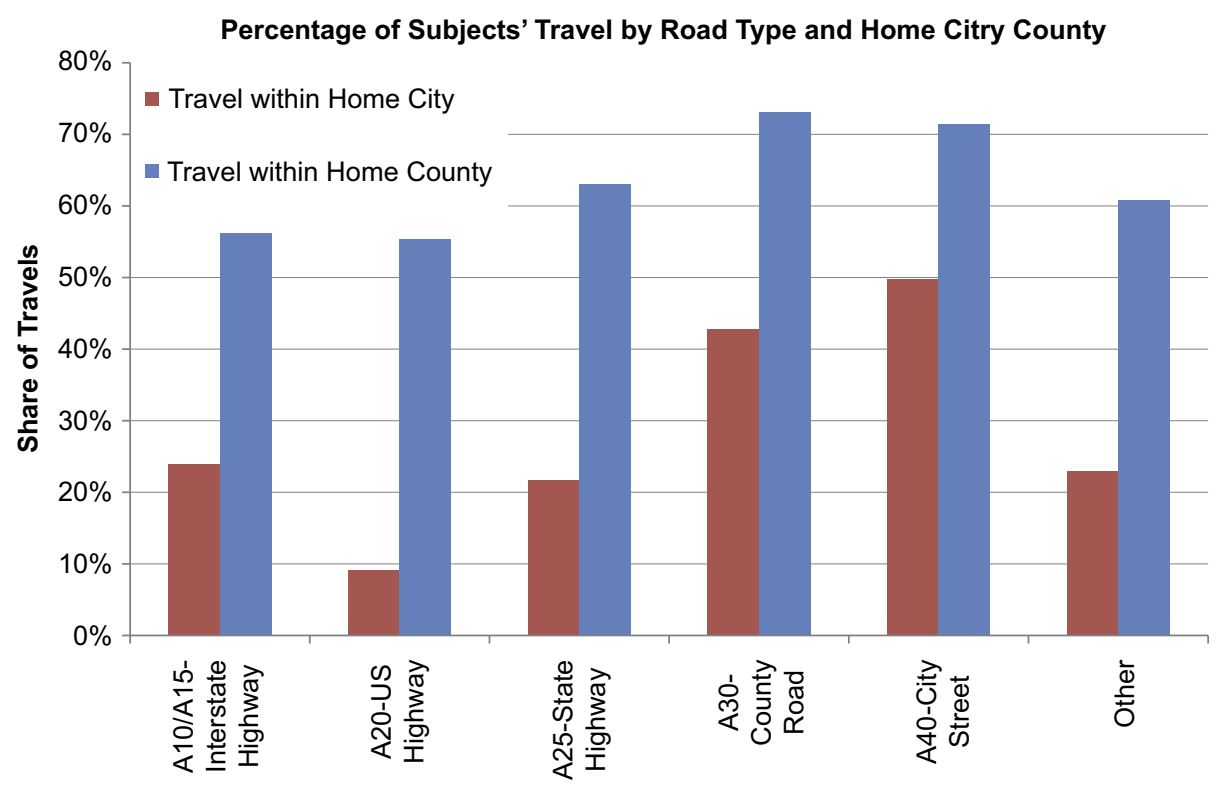

Fig. 5. Vehicle kilometers of travel on different road classes by home jurisdiction.

no value can be captured through activities/people at both ends of the trip (e.g., taxes paid by vendors or employers, or friends they visit). Fig. 7 summarizes the share of pure through traffic, measured by VKT taking place in one city (or county) which hosts neither end of the trip. The share of through traffic is relatively low for county, which is not surprising given the relative large size of counties. The problem of "free riders" is more significant for cities. About $22 \%$ and $13 \%$ traffic on county roads and city streets, respectively, is through traffic. Although the share is much higher for interstate highways, US highways, and state highways, they pose no problem since they are funded differently.

\section{Discussion}

The correspondence between the locality of travel and road ownership has not been adequately studied in the literature, although travel statistics by road classes and by jurisdiction has a long history. Many MPOs (e.g., San Francisco Bay Area MTC, 2011) have documented their local traffic by road classes for a long time. Bureau of Transportation Statistics (2011) tabulated national Vehicle Kilometers Traveled by functional class since 1980 . However, these traffic statistics are not associated with trip ends, thus cannot provide evidence to bear on the question of the locality of travel and road ownership correspondence. The National Household Travel Survey (NHTS, 2011) does provide the geographic locations of trip origins and destinations, as well as demographic information of travelers. However, NHTS does not record which path travels have followed. Although assumptions such as shortest time path can be made to derive such information, this assumption lacks accuracy and the conclusion relies heavily on modeling assumptions. Moreover, it is extremely difficult to analyze local traffic in this way because the number of alternative routes is large and many local streets do not exist in the planning model network. 


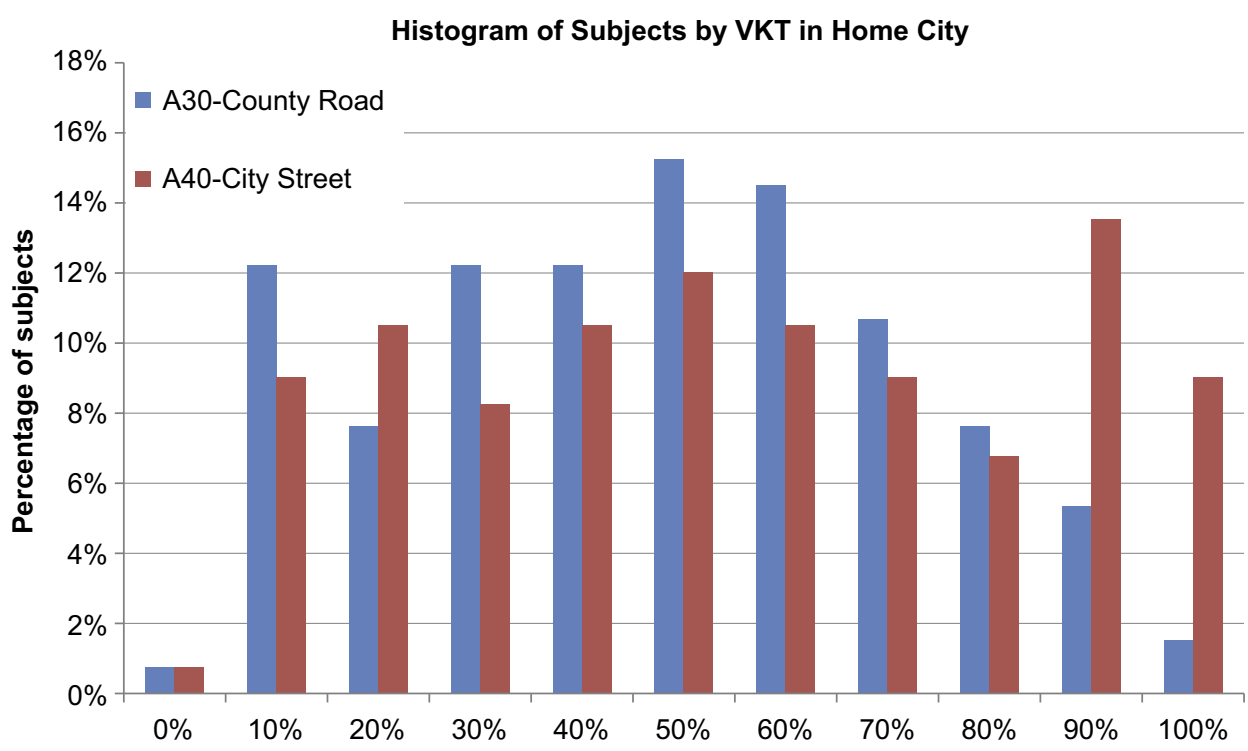

Fig. 6. Histogram of subjects according to the percentage of travel in one's home city.

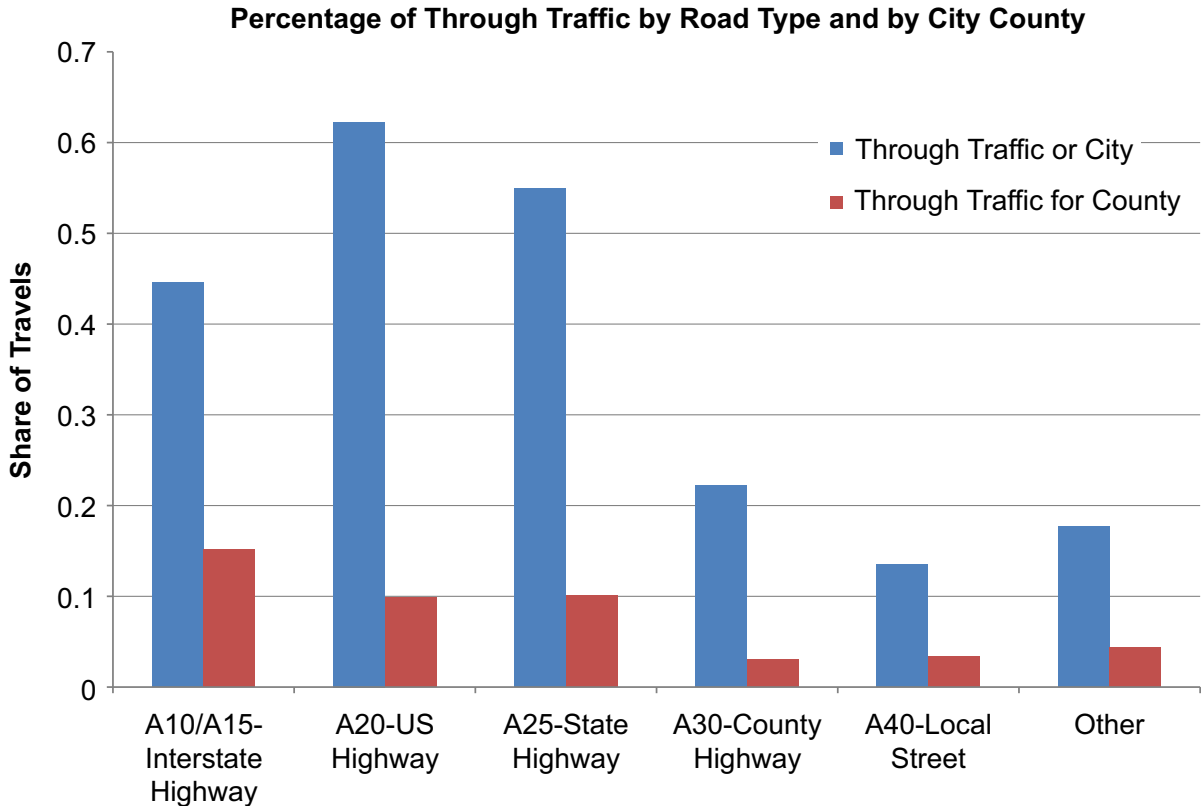

Fig. 7. Through traffic on different road classes by city and county (measured in VKT).

This study provides a way to address this question, which can be easily extended as new high resolution travel data (e.g., collected by vehicle GPS, electronic toll transponders, bluetooth devices, and smart phones) and detailed GIS maps become available. Sampling biases that may exist in this study due to high percentage of commuters can be better addressed with a larger data set. Given that the size of county (or city) varies immensely across the US (and around the world), analysis based on local data is crucial for deciding the best local policy. There is thus a need to periodically reconsider how governance of roads is arranged with evolving traffic conditions and technological advances in road management.

\section{Conclusion}

This paper provides evidence on the extent to which travel is localized across the hierarchy of roads, using GPS-based data on a group of subjects' travel in both time and distance on various types of functional classes of roads. In this study, more than half of the travel on county roads and city streets occur outside of one's home city, but most travel is within one's home county. Of particular concern is travel on city roads in cities other than one's own. To the extent that this is to go to a destination in that city, that travel is also local. However, because city and county roads are typically funded by those jurisdictions from land-based sources such as property taxes, through trips, with neither end in the city through which they are traveling, are in a very real sense "free riders", and pose a problem. That problem can be solved in various ways: reclassifying the road to a higher jurisdiction, changing municipal road finance to be use-based rather than land-based, making other routes more desirable, or making that road less desirable for traveling. Each of those alternatives raise new sets of issues.

Despite some free-riding problem, the current structure of local road finance has many useful features. Local forms of taxation, like property taxes and special assessments, are relatively easy and 
inexpensive to administer. As the current study has indicated, a large share of travel seems to be quite localized, with the implication that the users are broadly representative of those who bear the tax burden. Also, with some modifications to financing arrangements, issues with temporal and spatial free-riding can be minimized (e.g., Levinson, 2005).

There are also shortcomings to this approach. To the extent that local roads suffer congestion (and some collectors and minor arterials surely do), fixed charges will not be of much use in managing congestion. The price signal to users regarding the cost of road provision is weak. Likewise, the efficiency argument for property tax financing is weak in the case of heavy vehicles, which may impose disproportionately higher damage costs. Finally, the ability to charge through-trips is effectively prohibited.

This study provides a general idea about re-assessment and a suggestion that in this case, counties might be more appropriate for some roads with through trips (and cities for roads with few through trips). However, institutional capacity of local government (city or county) varies significantly across the country. Decisions would have to be negotiated between jurisdictions, or conducted at the state level, which has ultimate authority over most municipal decisions.

There is also a need to periodically reconsider how governance of roads is arranged. With growing trip lengths and emerging economies of scale in road management, it may be appropriate to consider moving more roads from township, town, or city level to the county level of government. There is not a universal rule for such a movement, but useful heuristics can be developed with further research.

\section{Acknowledgments}

The authors would like to acknowledge Michael Scharenbroich and Michael Iacono, who contributed on an earlier version of this work. This material is based in part upon work supported by the National Science Foundation under Grant No. 0825768, BRIDGE: Behavioral Response to the I-35W Disruption: Gauging Equilibration; Minnesota Department of Transportation project Traffic Flow and Road User Impacts of the Collapse of the I-35W Bridge over the Mississippi River; Oregon Transportation Research and
Education Consortium for the project Value of Reliability; and the University of Minnesota Metropolitan Consortium. We would also like to thank Kathleen Harder, John Bloomfield, Randy Guensler, and Shu Hong. Any opinions, findings, and conclusions or recommendations expressed in this material are those of the authors and do not necessarily reflect the views of the National Science Foundation, Minnesota Department of Transportation, Oregon Transportation Research and Education Consortium or others.

\section{References}

Buchanan, J., Tullock, G., 1962. The Calculus of Consent: Logical Foundations of Constitutional Democracy. University of Michigan Press.

Bureau of Transportation Statistics, 2011. Roadway Vehicle-Kilometers Traveled (vkt) and vkt per Lane-Kilometers by Functional Class, URL $\langle$ http://www.bts. gov/publications/national_transportation_statistics/html/table_01_36.html $\rangle$ (accessed online on June14 2011).

Craig W 2005. White knights of spatial data infrastructure: The role and motivation of key individuals. Editors and Review Board, vol. 16, Citeseer, p. 5

Durrenberger, J., 1931. Turnpikes; a study of the toll road movement in the middle Atlantic states and Maryland by Joseph Austin Durrenberger. Southern Stationery and Printing Co.

Hayek, F., 2001. The Fatal Conceit: The Errors of Socialism. Columbia University Press.

Levinson, D., 2002. Financing Transportation Networks. Edward Elgar.

Levinson, D., 2005. Paying for the fixed costs of roads. Journal of Transport Economics and Policy, 279-294.

Levinson, D., Yerra, B., 2002. Highway costs and efficient mix of state and local funds. Transportation Research Record: Journal of the Transportation Research Board 1812, 27-44.

McCabe, B., Tao, J., 2006. Private governments and private services: Homeowners associations in the city and behind the gate. Review of Policy Research 23, 1143-1157.

NHTS, 2011. National Household Travel Survey, URL <http://www.bts.gov/programs/ national_household travel_survey/> (accessed online on June 14 2011).

San Francisco Bay Area MTC, 2011. Regional Indicators, URL <http://www.mtc.ca. gov/maps_and_data/datamart/stats/ $>$ (accessed online on June 14 2011).

Tiebout, C., 1956. A pure theory of local expenditures. Journal of Political Economy 64, 1143-1157.

Wachs, M., 2003. Improving efficiency and equity in transportation finance. Brookings Institution, Center on Urban and Metropolitan Policy.

Xie, F., Levinson, D., 2009. Governance choice on a serial network. Public Choice $141,189-212$.

Zhu, S., Levinson, D., Liu, H., 2010. Measuring Winners and Losers from the new I-35W Mississippi River Bridge. In: Transportation Research Board 89th Annual Meeting Compendium of Papers DVD 10-2298, January 2010 Washington DC. 